\title{
Analysis of Macro-micro Simulation Models for Service-Oriented Public Platform: Coordination of Networked Services and Measurement of Public Values
}

\author{
Yumiko Kinoshita \\ Doctorate, Graduate School of Interdisciplinary Informatics, The University of Tokyo, \\ Research Fellow, Japan Society for the Promotion of Science \\ 7-3-1 Hongo, Bunkyo-ku, Tokyo, 113-0033, Japan \\ kinoshita.yumiko@iii.u-tokyo.ac.jp
}

\begin{abstract}
When service sectors are a major driver for the growth of the world economy, we are challenged to implement service-oriented infrastructure as e-Gov platform to achieve further growth and innovation for both developed and developing countries. According to recent trends in service industry, it is clarified that main factors for the growth of service sectors are investment into knowledge, trade, and the enhanced capacity of micro, small, and medium-sized enterprises (MSMEs). In addition, the design and deployment of public service platform require appropriate evaluation methodology. Reflecting these observations, this paper proposes macro-micro simulation approach to assess public values (PV) focusing on MSMEs. Linkage aggregate variables (LAVs) are defined to show connection between macro and micro impacts of public services. As a result, the relationship of demography, business environment, macro economy, and socio-economic impact are clarified and their values are quantified from the behavioral perspectives of citizens and firms.
\end{abstract}

Keywords: Macro-micro simulation models, linkage aggregate variables, e-Gov, service-oriented public infrastructure, public value.

\section{Introduction: Service Innovation}

\subsection{Service Technology and Changing Landscape}

A variety of information and communication technologies (ICT) are being developed to implement innovative services so that the needs of today's economy will be met[1, 2]. For an experimental research project for lifestyle related diseases, sensor network is used to collect information so that national healthcare system, medical insurance system, and e-Gov should be designed in an evidence-driven manner[3]. Data for research and development (R\&D) are interlinked, indexed, and organized. The practice and management of R\&D is refined where a good match of demand and solution is made through web-based database of solution provider. For instance, there is a collaborative information network such as Cancer Biomedical Informatics Grid ${ }^{1}$, which promotes

\footnotetext{
${ }^{1}$ https://cabig.nci.nih.gov/ 
communication related to $\mathrm{R} \& \mathrm{D}$. These kinds of collaborative activities contribute to the growth of service sectors[1].

ICT has a huge impact on innovativeness, adaptability, and quality of service development[4]. Atkinson and Castro[5] describe a list of benefits, which ICT can bring. Among those is the benefit for developing countries. In 2008, Pfizer and Grameen Health (GH) announced a partnership for healthcare delivery and financing for the exchange of expertise knowledge, and the improvement of micro health insurance, telemedicine and mobile healthcare[6]. It is considered that mobile technologies play a critical role as a low-cost infrastructure. The World Economic Prospect $(2008,2009)$ summarized by the World Bank[7, 8] articulate that the recent financial turmoil is bringing substantial uncertainty to developing countries due to swings of food and fuel prices, and that demand for commodities is not expected to outstrip supply over the long run. These new services offer channels for financing and commercialization, and access to education, healthcare, and expertise knowledge for micro, small and medium sized enterprises (MSMEs) ${ }^{2}$ and people who did not have access to any of those before. To continue to drive such technological innovation and, hence, promote service innovation[1, 2], we may need to focus on the important, dynamic role of MSMEs and third-party to play, and facilitate the co-evolutionary process of ICT with other technological fields[11] i.e. biotechnology and nanotechnology.

In today's socio-economic context, innovation in ICT holds three-faced importance in relation to services: networking of knowledge and expertise, the promotion of business and trade particularly for MSMEs, and a new solution for the development of global economy through service-oriented infrastructure.

\subsection{Service Innovation and Macro Economy}

The performance of service industry varies widely from sector to sector even in developed countries where service industry already consists $65-75 \%$ of the economy. As previously stated, innovation is achieved through networking of knowledge. However, the level of R\&D investment in services is still lower than those of the other sectors[12]. The government of the United Kingdom observes that service sectors draw heavily on suppliers and external partners for seeking expertise[4]. Service sector growth led by trade is considered as a vital factor for current and future economic growth. Finland has transformed its economy into service-dominated market by focusing on knowledge intensive services (KIS) ${ }^{3}[13]$. KIS influence the business performance of organizations and value chains as they contribute to some types of technological and service innovation directly and form a link of technologies and knowledge beyond sectors $[14,15]$.

${ }^{2}$ One definition of Micro, small and medium-sized enterprises (MSMEs) is 'enterprises which employ fewer than 250 persons and which have an annual turnover not exceeding 50 million euro, and/or an annual balance sheet total not exceeding 43 million euro.' For a detailed description used in Europe, see Article 2 of the Annex of Recommendation 2003/361/EC[9]. Also, refer to Ayyagari, Beck, and Demirguc-Kunt[10] for a summary of various definitions currently used in the world.

${ }^{3}$ Knowledge-intensive services (KIS) are also referred to as 'Knowledge-intensive business services (KIBS)' and 'Knowledge-intensive service activities (KISA).' 

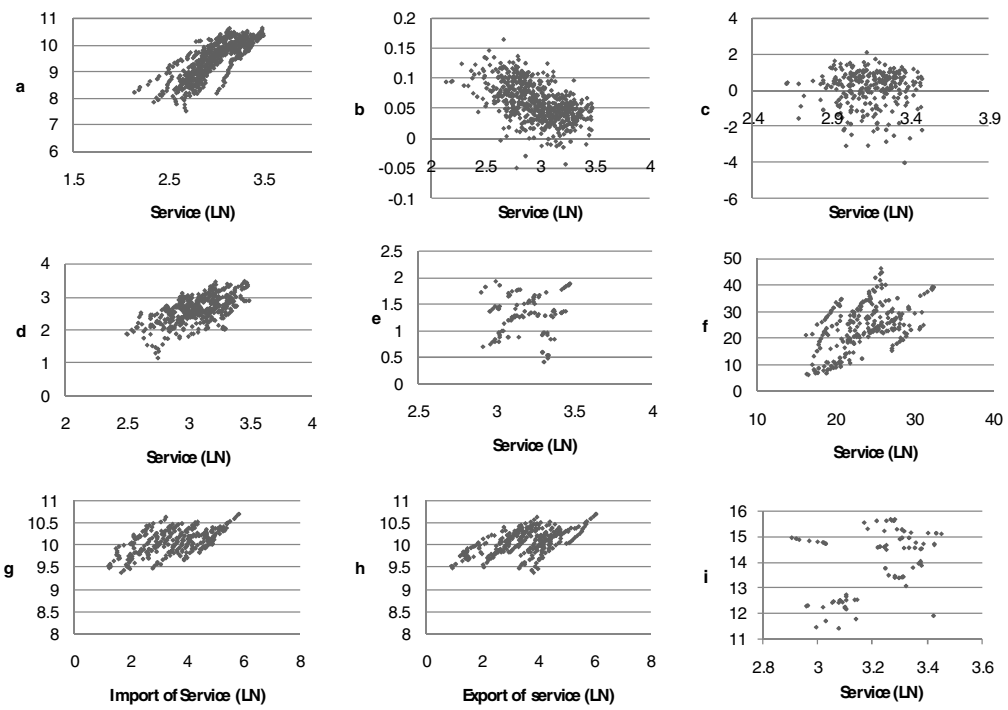

Fig. 1. Commercial Services and Macroeconomic Indicators. *Country: Australia, Austria, Canada, Denmark, Finland, France, Germany, Italy, Ireland, Japan, Netherlands, New Zealand, Portugal, Spain, Sweden, Switzerland, United Kingdom, and United States. **Service (ln): Value added in banks, insurance, real estate and other business services (as percentage of total value added) in 1990-2006; (a) GNI per capita (US dollars, current prices and PPPs); (b) GNI per capita growth rate; (c) MFP (annual growth in percentage); (d) Shares of ICT investment in non-residential gross fixed capital formation (as a percentage of total non-residential gross fixed capital formation); (e) Tertiary attainment for age group 25-64 (as a percentage of the population of that age group); (f) Investment in knowledge (as a percentage of GDP); (g) Gross national income per capita and Imports of services (Bil US dollars); (h) GNI per capita and Exports of services (Bil US dollars); and (i) MSMEs' Participation in the Economy (ln) as a number of companies during 1997-2006. Data source: OECD[18], WTO[16], and IFC[19].

Fig. 1 shows a summary of recent macroeconomic trends regarding service sectors. Service sectors tend to take up a large market share when the following indicators are high: gross national income (GNI) per capita (Fig. 1a), the shares of ICT investment (Fig. 1d), the investment into knowledge (Fig. 1f), and the participation of MSMEs in the economy (Fig. 1i). Also, both export and import tend to increase according to the growth of service industries (Fig. 1g and Fig. 1h). Trade volume is growing particularly in European countries (especially within Europe) and Asian \& Pacific countries[16]. On the other hand, either GNI growth rate (Fig. 1b), multi-factor productivity (MFP) (Fig. 1c), or tertiary attainment (Fig. 1e) does not seem to give a substantial influence on the trend of service industry. These data are insufficient to determine a cause-effect relationship although, in general, it is consistent to the observations presented in the previous section.

The following sections of this paper will be dedicated for the analysis of service-oriented e-Gov infrastructure designed for the support of MSMEs. The goal of the analysis is to propose a method to evaluate public values (PV)[15]. This attempt is in 
response to the needs of today's e-Gov initiative, which is to clarify PV from individual users' perspectives at an organization level[17].

\section{Service-Oriented Public Architecture}

\section{1 e-Gov Platform for the Support of MSMEs}

The activity of MSMEs can be supported with public service-oriented infrastructure according to Borresen[20], Stauning[21], and Brun and Lanng[22]. MSMEs and public institutions are linked via a master registry.

According to Ayyagari, Beck, and Demirguc-Kunt[10] who studied SMEs and business environment by country, low entry cost (especially for property registration), easy access to financial capital, and greater information sharing are important for the success of large SMEs in manufacturing sector. The service-oriented infrastructure for MSMEs is designed for lowering barriers to promote the participation of smaller enterprises by optimizing business operation and reducing administration costs through shared infrastructure. The other desired elements are building web-based database on firms for accountability and transparency, promoting peer-to-peer payment mechanisms to meet personal service needs and activity-based service charge, harvesting long-tail of service business, and creating new services through enhanced interaction between vendors and users as well as external professionals. As previously stated, the support of MSMEs has an implication of future inter-governmental e-Gov network, which would facilitate service trade and provide a solution to the global issues.

Based on these preliminary observations, the possible components of the public service-oriented architecture for the support of MSMEs are e-tax, sourcing, cataloging, billing, ordering, data sharing on firm's business profile, and consultation (Fig. 2). The portal for MSMEs is linked to public database and private networks i.e. commercial banks. It is also connected to citizen's one-stop portal so that MSMEs are able to access information of job seekers. These portals are desired to be linked to networks provided by foreign governments to facilitate worker mobility across national borders and firm's entry into the global market. The portal is going to be analyzed according to the definition of PV to be explained in the next section.

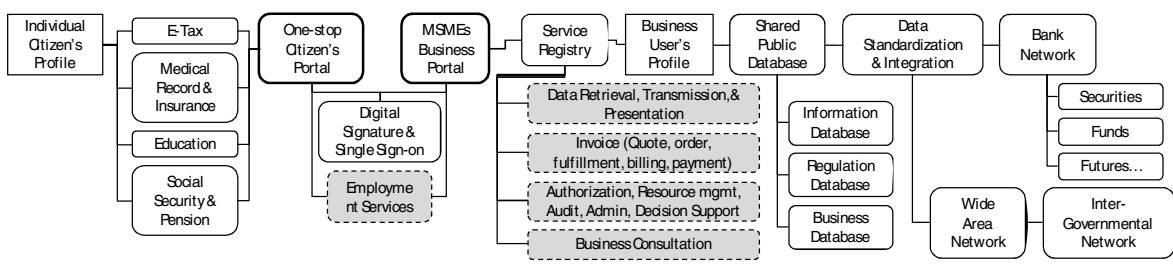

Fig. 2. Open Service-oriented e-Gov Infrastructure for MSMEs. Source: Author's depiction according to Borresen[20], Stauning[21], Yongxiang[23], EURES[24] and Brun et al.[22]. 


\subsection{Analysis of Public Value Chain and Scope of Problem}

There are various ways to define PV. One of those is presented by Sudoh, Gotoh, Akatsu, Yoshikawa, Nakagawa, and Kinoshita[25], who defined PV of e-Gov as an aggregate of economic, program, political, societal, and innovative value (Fig. 3).

Economic value refers to gross domestic product (GDP) per capita and external effects. Program value is represented by efficiency, effectiveness, and governance. This category directly and indirectly relates to technical aspects i.e. usability, utilization and scalability. Political value is generated from transparency, participation of citizens, trust, and equality, which are also understood as governance. Societal value is comprised of health, welfare, environment and regional management. Lastly, innovative value refers to industrial growth and creation of new services in both public and private sectors, which would affect national competitiveness.

\begin{tabular}{|c|c|c|c|c|c|c|c|c|c|c|c|c|c|c|}
\hline $\begin{array}{c}\text { GDPper } \\
\text { capita }\end{array}$ & $\begin{array}{l}\text { External } \\
\text { Efect }\end{array}$ & $\begin{array}{l}\text { Efici } \\
\text { ency }\end{array}$ & $\begin{array}{c}\text { Efectiv } \\
\text { eness }\end{array}$ & $\begin{array}{l}\text { Govern } \\
\text { ance }\end{array}$ & $\begin{array}{l}\text { Transp } \\
\text { arency }\end{array}$ & $\begin{array}{l}\text { Partia } \\
\text { pation }\end{array}$ & $\begin{array}{l}\text { Tru } \\
\text { st }\end{array}$ & $\begin{array}{l}\text { Equ } \\
\text { ality }\end{array}$ & $\begin{array}{l}\text { Hea } \\
\text { Ith }\end{array}$ & $\begin{array}{l}\text { Wel } \\
\text { fare }\end{array}$ & $\begin{array}{l}\text { Enviro } \\
\text { nment }\end{array}$ & $\begin{array}{c}\text { Pegional } \\
\text { Mgmt }\end{array}$ & $\begin{array}{l}\text { Industry } \\
\text { Growth }\end{array}$ & $\begin{array}{c}\text { New } \\
\text { Serviœes }\end{array}$ \\
\hline
\end{tabular}

Fig. 3. Public Values (PV) for e-Gov. Source: Sudoh et al.[25].

With regard to the value chain for the portal can be depicted as the next flowchart (Fig. 4). Each box with a solid line is an account of incident in correspondence to possible events occurred. These can be understood further with behavioral approaches. Each box with a dotted line represents either an economic structural framework or qualitative values for the public sector. Both of them must be represented by micro-simulation models with appropriate endogenous and exogenous variables analyzed in logit, probit, linear and logistic regression, and/or Monte Carlo. In the next section, macro and micro simulation models will be discussed in detail.

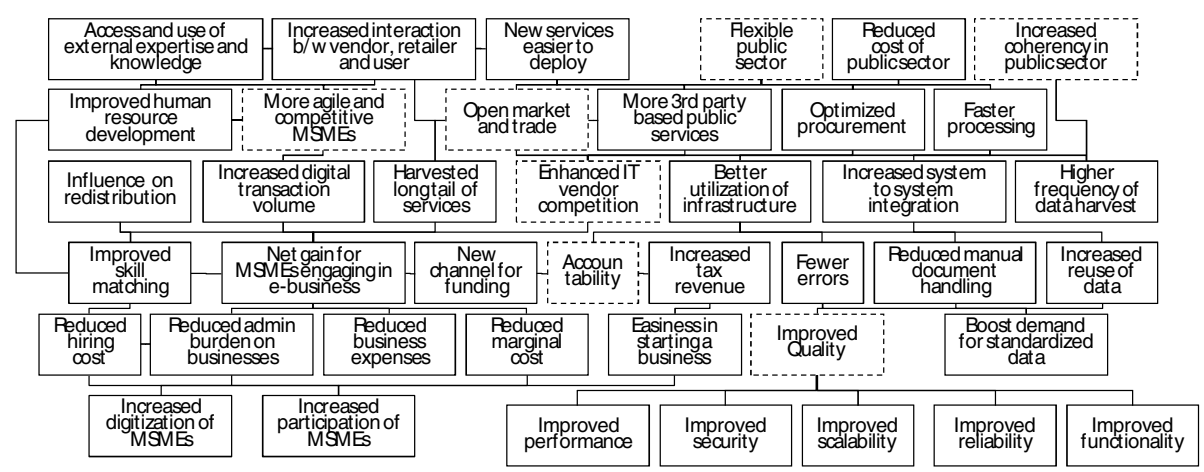

Fig. 4. Value Chain for MSME Business Portal. Source: Author's depiction according to Borresen[20], Stauning[21] and Brun et al.[22]. 


\section{Discussion on Simulation Models}

\subsection{Macro-micro Simulation Models}

The macro-micro simulation is composed of two sets of methodology: one is macro techniques, and the second is micro techniques. Macro and micro models are combined with different degrees of integration[26]. The macro-micro approach allows assessing the micro effects of macroeconomic policy changes.

From macroeconomic perspectives, we need computation models to build structural models with assumptions i.e. utility-maximizing consumer under a budget constraint with tax-benefit system via the one-stop portal. After structural impact is simulated with macro models, results are imputed into micro models (top-down) or vice versa (bottom-up). Micro-simulation models (MSMs) 'allow simulating the effects of a policy on a sample of economic agents at the individual level' [27]. The approach is useful for the assessment of heterogeneous population over representative approach. It deals with various combinations of social and behavioral characteristics to clarify a mechanism by which individuals are allocated to the policy to receive benefits[28]. Behavioral heterogeneity is observed in source information and exogenous factors[29]. This paper incorporates linkage aggregate variables (LAVs)[26] to find a loop for the feedback between macro and micro models. PV are then clarified as an aggregate of marginal effects on LAVs.

\subsection{Application to the Scheme of e-Gov: Structure of Models}

This section will discuss the structure and relationship of each component of the methodology as a proposal for the measurement of PV for MSME Business Portal (Fig. 5). In the first step, the service infrastructure is designed according to the trend of macro economy to meet the needs of individuals facing a certain socio-economic environment (top-down loop). The infrastructure is analyzed by using micro models as well as technological assessment models. Consolidating findings makes LAVs, and data is imputed into macro models (bottom-up loop).

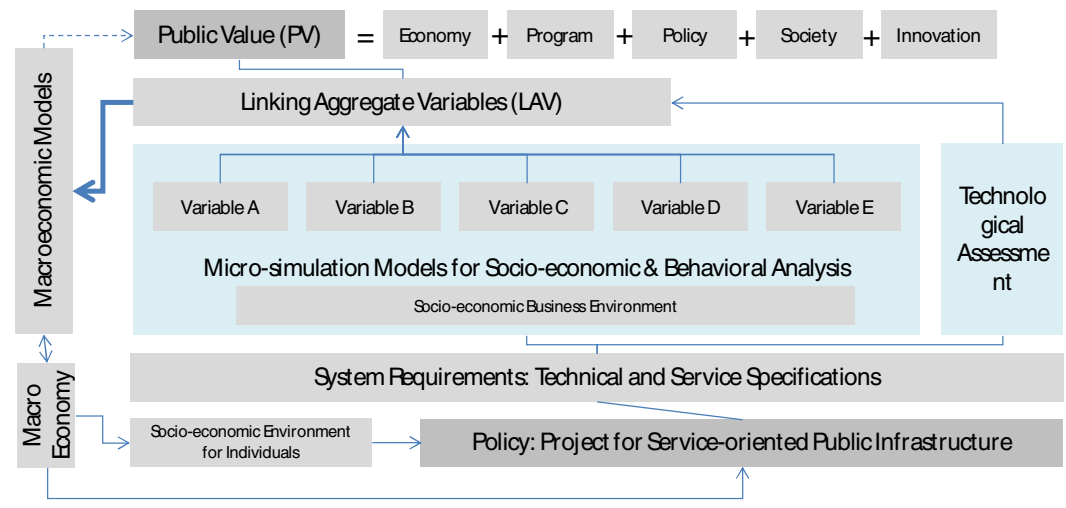

Fig. 5. Assessment Framework for MSME Business Portal (proposed) 
In the following sections, the relationship between macro economy and socio-economic environment for individuals will be explained. Then, the micro-simulation models for socio-economic and behavioral analysis will be clarified including the analysis for socio-economic business environment. There is a discussion on technical assessment. Lastly, the relationship of macroeconomic models will be clarified followed by the definition of LAVs.

\subsection{Assessment Methodology}

\section{Socio-economic Environment for Individuals}

Societal value deals with ex ante and ex post socio-economic conditions to evaluate how the portal will affect individuals and households as a result of linking personal information on tax, healthcare, education, social security, and employment. This category is largely related to the societal value. The target population is individuals $(N)$ or of his or her family, who does or has potential to work with MSMEs or who owns a MSME. The outcomes and events below are to be considered[30].

- Education: exit from university, secondary education, or adult education to labor force, entry from labor market to university or adult education, exit from adult education to labor force, occupational training.

- Labor market and status: retirement, unemployment, employment, part-time or full-time, occupation change (compensated sickness days, spouse or other household member's working status).

- Financial and real wealth: housing (own/rent), cost of living, financial wealth inc. pension, interest, dividends, capital gains, other real wealth, debt.

- Tax \& Transfers: disposable income, loans, tax, allowance, earnings.

- Noncash benefits: child care, care for elderly, compulsory education, healthcare, medication, take-up of social assistance.

Macroeconomic indicators are given as exogenous variables, for example, annual rate of change in inflation (CPI), annual real general increase in wage rates, net interest rate, dividends, and change in prices on stocks and shares[30]. Also, social index and status are given i.e. working experience, highest education, occupational sector, nationality, marital status, health status, family composition.

\section{Business Environment}

The second category of assessment is business environment, which would be greatly improved with the utilization of the portal. This category is related to program or policy values. The following items are analyzed based on World Bank Doing Business Database[31] according to the functionality of the system.

- Easiness of starting a business: the number of procedures reduced, time reduced, cost reduced, the number of errors reduced. 
- Effectiveness in employing workers: skill matching improved, hiring cost reduced, depth of information improved, the number of people using the system increased, time reduced from posting until hiring.

- Effectiveness in getting credit: depth of credit information index improved, extent of disclosure index improved.

- Efficiency in paying taxes: the number of tax payments and procedures reduced, time reduced to prepare, file and pay, cost reduced, the number of errors reduced.

- Increased trading across borders: the number of procedures reduced for export and import, time reduced, cost reduced, the number of errors reduced.

- Effectiveness in closing a business: recovery rate in bankruptcy improved, time reduced, cost reduced, the number of errors reduced.

Covariates are, for example, the number of new regulation, the number of MSMEs participating in the system, industry sector, industry output growth, mobility of workers, wage rate, availability of legal remedies, strength of investor protection, court and attorney's fee, and appreciation and depreciation of assets.

\section{Micro-simulation Models for Socio-economic and Behavioral Analysis}

To build micro models for the agent $i$ with characteristics $z$, we take parameters of preference $\left(\beta_{i}\right)$, parameters of idiosyncratic preference $\left(\varepsilon_{i}\right)$, and the access to business portal system or one-stop portal $(\gamma)$ [27]. Social welfare function $(S W F)$ is:

$$
\operatorname{SWF}(\gamma)=\sum_{i=1}^{n} V\left[U\left(z_{i}, \beta_{i}, \varepsilon_{i} ; \gamma\right)\right]
$$

$U(\cdot)$ is the utility function, and $V[\cdot]$ is the social valuation of individual welfare.

The utility function is therefore:

$$
\max u\left(c_{i}, L_{i} ; z_{i} ; \beta_{i}, \varepsilon_{i}\right) \text { s.t. } c_{i} \leq y_{0 i}+w_{i} L_{i}+S W F(\gamma), L_{i} \geq 0
$$

in which consumption $\left(c_{i}\right)$, labor supply $\left(L_{i}\right)$, the initial level of labor income $\left(y_{0 i}\right)$, wage rate $\left(w_{i}\right)$ are considered. This social welfare function is compared to that of when the portal system is absent.

When we estimate $\hat{\beta}_{i}$ and $\hat{\varepsilon}_{i}$, changes in labor supply and consumption are:

$$
\begin{gathered}
L_{i}-L_{i}^{0}=L_{i}-F\left(w_{i}, y_{0 i} ; z_{i} ; \hat{\beta}_{i}, \hat{\varepsilon}_{i} ; 0\right)=F\left(w_{i}, y_{0 i} ; z_{i} ; \hat{\beta}_{i}, \hat{\varepsilon}_{i} ; \gamma\right) \\
C_{i}-C_{i}^{0}=w_{i}\left(L_{i}-L_{i}^{0}\right)+S W F(\gamma)-S W F(0)
\end{gathered}
$$

We observe how the portal would affect wage rate due to the reduction of costs for hiring. With regard to industry and firm behavior, we can analyze how the knowledge intensiveness in labor force will improve labor productivity. Therefore, we need to observe how this system would affect capital investment behavior in macro models. The resulting capital-labor ratio (K/L) will influence industry output. 


\section{Technological Assessment}

Technological factors are generally grouped into performance $(P)$, security $(S e)$, functionality $(F)$, reliability $(R)$ and scalability $(S c)$, which directly influence quality and hence the take up of system by the users. In a complex behavioral model, such factors as user's perception, level of satisfaction, and objective/subjective quality should be taken into account. These factors are reactive to the metadata scheme underlining web-based services, which define user groups, a role of agent, interaction sequence and the like. This type of data scheme has been used in, for instance, electronic health record (EHR)[32]. When we study how these aspects would impact and relate to the micro models, the following equation is derived for technological factors for the agent $i$ with an attribute set $z$ :

$$
T(z)=\sum_{i=1}^{n} T I\left[Q(P, S e, F, R, S c), D\left(e_{i}, z_{i} ; a_{i} ; i, r ; \gamma\right)\right]
$$

in which we take entity $\left(e_{i}\right)$, action $\left(z_{i}\right)$, interaction $(i)$, relationship $(r)$, and system specific metadata scheme $(\gamma) . Q(P, S e, F, R, S c)$ is an (objective) quality function, and $D\left(e_{i}, z_{i} ; a_{i} ; i, r ; \gamma\right)$ is a data function. $T I[\cdot]$ is the program specific valuation of technological impact. These factors will give an impact on system-to-system integration, data standardization efforts, and hence increased coherency in public sector and the flexibility of public sector. These resulting values are related to policy value (in particular, governance).

\section{Macroeconomic Models}

There are a variety of macroeconomic models, which can be employed for the assessment of MSME Business Portal. Based on the behaviors observed in micro models, it is important to consider how the system influence cost of producing a unit of products, wage rate and labor productivity, profit of firms according to the size of firms and sectors, and export and import of heterogeneous products. Industry and firm behaviors must be modeled properly for both short-term and long-term decisions. As for macroeconomic models, we can take the following equations[33]. The production $(Y)$ for country $j$ at time $t$ is:

$$
Y_{j t}=A_{t} K_{j t}^{\theta} L_{j t}^{1-\theta}
$$

where $\theta$ is $0<\theta<1$ with productivity $(A)$, capital $(K)$ and labor $(L)$. The capital stock is given as:

$$
K_{j t+1}=(1-\delta) K_{j t}+X_{j t}
$$

$X_{j t}$ is investment in intermediaries, and $\delta$ is depreciation rates. Aggregate output $(Y)$ consists of consumption $(C)$, government expenditures $(G)$, investment $(I)$, and the current account $(C A)$ surplus.

$$
Y_{j t}=C_{j t}+X_{j t}+G_{j t}+C A_{j t}
$$


Taxable profits are equal to sales less expenses, which are wage payments, tangible depreciation, and expensed investments on intermediaries. The household utility is

$$
\max _{\left\{c_{j t}, K_{j t+1}\right\}} \sum_{t=0}^{\infty} \beta^{t} N_{j t}\left[\log c_{j t}\right]
$$

in which $c_{t}$ is per member consumption at time $t . \beta$ is a parameter. $N_{t}$ is working-age population. Marginal utility of household is:

$$
\frac{c_{j t+1}}{c_{j t}}=\beta\left[1+\left(1-\tau_{K}\right)\left(r_{t+1}-\delta\right)\right]
$$

with tax on capital income $\left(\tau_{K}\right)$ and $r$ is the rental rate of capital. The budget constraint of the household is:

$$
C_{j t} \prec w_{j t} L_{j t}+r_{j t} K_{j t}-\tau_{K}\left(r_{j t}-\delta\right) K_{j t}-\pi_{j t} I_{j t}-X_{j t}
$$

where $I_{j t}$ is personal income. We can also analyze cost-disadvantage ratio (CDR) to see if the system reduces fixed cost (FC) relative to total cost (TC), and how investment would be changed accordingly.

\section{Linkage Aggregate Variables (LAVs) and Public Values (PV)}

The solution of the micro simulation models provides LAVs. They are fed into macro models, and used for the calculation of PV. PV are measured as a marginal effect of each LAV. Based on all the equations, the following LAVs are defined.

- Economy: output $(Y)$, labor supply $(L)$, technology $(A)$, investment $(X)$, capital $(K)$, household consumption $(C)$, wage rate $(w)$, trade $(C A)$, utility $(u)$ (9 variables)

- Program: easiness of starting a business (4 outcomes), effectiveness in employing workers (5 outcomes), efficiency in paying taxes (5 outcomes), increased trading across borders (4 outcomes), technology/quality (5 parameters, by attributes)

- Policy: effectiveness in getting credit (2 outcomes), effectiveness in closing a business (4 outcomes), quality (5 parameters, by attributes)

- Society: wage rates (by sector, rate, skill level), occupation (by sector), price (\% changes, by sector), education (4 outcomes), labor (5 outcomes, 2 complements, by sector), financial and real wealth ( 3 outcomes, $\%$ changes, 5 types), tax (5 outcomes, $\%$ changes), noncash benefits ( 5 outcomes), social welfare ( 1 outcome)

- Innovation: sector growth (1 outcome), product variety (1 outcome), new entrants (1 outcome), new products and services (1 outcome)

\section{Summary and Conclusion}

In response to the recent trend of service industry and service-oriented technology, this paper proposes a method of measuring PV in e-Gov infrastructure by taking MSME Business Portal as a case study. This aims to design, implement and utilize service-oriented infrastructure for service innovation in response to today's socio-economic 
needs. The structure of measurement is structured in five components: socio-economic environment for citizens, business environment, technology, micro simulation, and macro economy. Linkage aggregate variables (LAVs) are specifically introduced so that micro impact of the policy is scaled up to macro perspectives, and that PV are clearly itemized and quantified. With this approach, the citizen's one-stop portal and MSMEs business portal can be analyzed in one sequence, and PV, which are consisted of various kinds of impacts on heterogeneous population, are quantified. The potential inter-governmental coordination in e-Gov initiatives and the role of trade are also incorporated into the model.

For further improvement of the methodology, it is important to test in real scenarios. In this sense, this paper does not comment on the type of data that we need to use. Since micro-level data have not been accumulated well with regard to e-Gov infrastructure, this paper focuses on simulation models rather than empirics. However, to discuss the impact that e-Gov would give to our society and economy, we must increase our efforts to build up firm-level panel data in relation to e-Gov. For future research, the macro-micro models should be tested using actual datasets, find appropriate indices for nonmonetary impact, and optimize methodologies to ameliorate the burden of computation.

Finally, as for a future scenario for the economic growth based on service innovation in line with public innovation, several areas must be considered. One area is an international implication of e-Gov. Currently multi-organizational coordination and business operation reforms are underway so that one-stop services are provided to citizens. For the next stage, international coordination of public services in e-Gov initiatives may be targeted. To solve global issues i.e. poverty, it is crucial to develop of competitive public infrastructure, and to provide better services for citizens to meet the needs of service-oriented economy. Financial, education and healthcare sectors must also orchestrate their efforts within and across countries for a faster economic recovery and growth. This is a collaborative effort to bring service innovation system into our daily life. It is what we need to target as the next stage of public innovation.

\section{Acknowledgment}

This work is supported by Grant-in-Aid for JSPS Fellows (No. 21· 166), MEXT, Japan. I appreciate Professor Osamu Sudoh, the University of Tokyo, who has offered deep insights on the concept of measuring innovation. The author is responsible for any possible mistake in this paper.

\section{References}

1. Sudoh, O.: The Knowledge Network in the Digital Economy and Sustainable Development. In: Sudoh, O. (ed.) Digital Economy and Social Design, pp. 3-38. Springer, Heidelberg (2005)

2. Council on Competitiveness, Innovate America (2004), http: / /www. compete.org/publications/detail/202/ innovate-america/ 
3. Sudoh, O., Inoue, S., Nakashima, N.: eService Innovation and Sensor Based Healthcare. In: Oya, M., Uda, R., Yasunobu, C. (eds.) Towards Sustainable Society on Ubiquitous Networks, pp. 1-14. Springer, Heidelberg (2008)

4. NESTA Policy \& Research Unit, Innovation in Services (2008), http: / / www. nesta.org.uk/assets/Uploads/pdf / Policy-Briefing / innovation_in_services_policy_briefing_NESTA.pdf

5. Atkinson, R.D., Castro, D.D.: Digital Quality of Life -Understanding the Personal \& Social Benefits of the Information Technology Revolution. Information Technology and Innovation Foundation (2008)

6. Bellinghen, D.V.: Grameen Health and Pfizer Announce Novel Partnership To Explore Sustainable Healthcare Delivery Models for The Developing World, Corporate news (September 24, 2008),

http: / / www.pfizer.be/Media/Press+bulletins /

Philantropy/Grameen+Health+and+Pfizer+Partnership.htm

7. The World Bank: Global economic prospects (2008)

8. The World Bank: Global economic prospects (2009)

9. European Commission: The new SME definition (2008), http://ec.europa.eu/enterprise/enterprise_policy/ sme_definition/sme_user_guide.pdf

10. Ayyagari, M., Beck, T., Demirguc-Kunt, A.: Small and Medium Enterprises Across the Globe. Small Business Economics 29, 415-434 (2007)

11. Sudoh, O.: Administrative Evolution and Open Innovation. Journal of Social Informatics Research 1(1), 147-160 (2008)

12. Miles, I.: Innovation in Services. In: Fagerberg, J., Mowery, D.C., Nelson, R.R. (eds.) The Oxford Handbook of Innovation, pp. 433-458. Oxford University Press, Oxford (2006)

13. Finnish Funding Agency for Technology and Innovation (TeKes): Serve -Innovative Internationally competitive business from service innovations (2007),

http: / /www. tekes.fi/serve

14. OECD: Innovation and Knowledge-Intensive Service Activities (2006)

15. Service Innovation Research Initiative: Proposal Towards the Establishment of an Informatical Foundation of Services to Realize Innovation. Division of University Corporate Relations, the University of Tokyo (2009),

http://www.ducr.u-tokyo.ac.jp/service-innovation/pdf/ 090331teigen-en.pdf

16. World Trade Organization, Time Series on International Trade (2009)

17. Kinoshita, Y., Sudoh, O.: Network-driven Context in User-driven Innovation. In: Oya, M., Uda, R., Yasunobu, C. (eds.) Towards Sustainable Society on Ubiquitous Networks, pp. 245-252. Springer, Heidelberg (2008)

18. OECD: Economic, Environmental and Social Statistics. OECD Factbook (2008), http: / / www . oecd.org/publications / factbook

19. International Finance Corporation, the World Bank: Micro, Small, and Medium Enterprises: A Collection of Published Data (2007)

20. Borresen, P.L.: OIOUBL -Case Study of How to Implement a Nationwide Procurement Standard. In: OASIS Symposium (2007)

21. Stauning, S.: Establishing a National Service Oriented eBusiness and eGovernment Infrastructure. In: OASIS Symposium (2007)

22. Brun, M.H., Lanng, C.: Reducing barriers for e-business in SME's through an open service oriented infrastructure. In: Proceedings of the 8th international conference on Electronic commerce, pp. 403-410. ACM, New York (2006) 
23. Yongxiang, W.: Information System Integration Project of China Securities Regulatory Commission (CSRC). In: OASIS Symposium (2007)

24. European Commission, EURES, http: / / www . europa.eu.int/eures /

25. Sudoh, O., Gotoh, R., Akatsu, M., Yoshikawa, H., Nakagawa, T., Kinoshita, Y.: Performance Measurement and Evaluation Framework for e-Government (To Be). e-Government Evaluation Committee's Report for the 2nd meeting, Division of University Corporate Relations, The University of Tokyo, Government report (July 26, 2007)

26. Bourguignon, F., Silva, P.D., Luiz, A.: Evaluating the Poverty and Distributional Impact of Economic Policies: A Compendium of Existing Techniques. In: Bourguignon, F., Silva, P.D., Luiz, A. (eds.) The Impact of. Economic Policies on Poverty and Income Distribution: Evaluation Techniques and Tools, The World Bank (2003)

27. Bourguignon, F., Spadaro, A.: Microsimulation as a tool for evaluating redistribution policies. Journal of Economic Inequality 4(1), 77-106 (2006)

28. Boccanfuso, D., Estache, A., Savard, L.: Electricity Reforms in Mali: A Macro-Micro Analysis of the Effects on Poverty and Distribution. Journal of African Economics 16(4), 629-659 (2007)

29. Essama-Nssah, B.: A Poverty-Focused Evaluation of Commodity Tax Options. World Bank Policy Research Working Paper No. 4245 (2007)

30. Lindgren, B., Klevmarken, A.: Simulating An Ageing Population: A Microsimulation Approach Applied To Sweden. Emerald Group Publishing (2008)

31. The World Bank: Doing Business Database (2009), http: //www. doingbusiness.org/Documents/FullReport/2009/ DB_2009_English.pdf

32. Health Level Seven, Inc.: Health Level Seven (HL7) Meta-Model, http: / /www.h17.org/

33. Hayashi, F., Prescott, E.: The 1990s in Japan: A Lost Decade. Review of Economic Dynamics 5(1), 206-235 (2002) 